\title{
Adubação nitrogenada em feijoeiro em sucessão a cultivo solteiro e consorciado de milho e Urochloa ruziziensis ${ }^{1}$
}

\author{
Michelle Traete Sabundjian², Orivaldo $\mathrm{Arf}^{2}$, Flávio Hiroshi Kaneko ${ }^{3}$, João Paulo Ferreira²
}

\begin{abstract}
Nitrogen fertilization on common bean in succession to maize and Urochloa ruziziensis single cropping and intercropping

The expansion of the no-tillage system, in Brazil, has increasingly diversified the ways in which the production methods are established and managed. This study aimed at evaluating the influence of preceding crops such as mayze and Urochloa ruziziensis, as well as their intercropping, in the presence and absence of seed inoculation with Azospirillum brasilense, and the cover nitrogen supplying on common bean development, production components and grain yield. The study was carried out in Selvíria, Mato Grosso do Sul State, Brazil, in the 2011/2012 crop season. The experimental design was randomized blocks, with four replications, in a $8 \times 4$ factorial scheme, with treatments consisting of a combination of cover crops (associations of mayze, $U$.ruziziensis and A. brasilense) and cover nitrogen doses on common bean $\left(0 \mathrm{~kg} \mathrm{ha}^{-1}, 30 \mathrm{~kg} \mathrm{ha}^{-1}\right.$, $60 \mathrm{~kg} \mathrm{ha}^{-1}$ and $\left.90 \mathrm{~kg} \mathrm{ha}^{-1}\right)$. The preceding crops affected the common bean grain yield, with the mayze and Urochloa intercropping, both inoculated, being the best option. The initial common bean population was not affected by previous crops. The cover nitrogen application did not affect the common bean grain yield under winter irrigation, for the no-tillage system.
\end{abstract}

KEY-WORDS: Azospirillum brasilense; cover crops; mineral nitrogen.

\section{INTRODUÇÃO}

A expansão do sistema plantio direto, no Brasil, está, cada vez mais, diversificando as formas como os sistemas de produção são implantados e manejados. Assim, executar sucessão de culturas após lavouras consorciadas com forrageiras já é uma realidade, pois há crescente preocupação com a sustentabilidade dos agrossistemas (Tsumanuma 2004).

\section{RESUMO}

A expansão do sistema plantio direto, no Brasil, está diversificando, cada vez mais, as formas como os métodos de produção são implantados e manejados. O presente estudo objetivou avaliar a influência de culturas antecessoras como o milho e Urochloa ruziziensis, bem como o consórcio entre estas, na presença e ausência de inoculação de sementes com Azospirillum brasilense, e o fornecimento de nitrogênio em cobertura sobre o desenvolvimento do feijoeiro e de seus componentes de produção e produtividade de grãos. O trabalho foi desenvolvido em Selvíria (MS), na safra 2011/2012. O delineamento experimental foi o de blocos ao acaso, com quatro repetições, em esquema fatorial $8 \times 4$, cujos tratamentos foram constituídos pela combinação de restos culturais (associações de milho, U. ruziziensis e A. brasilense) e doses de nitrogênio em cobertura no feijoeiro $\left(0 \mathrm{~kg} \mathrm{ha}^{-1}, 30 \mathrm{~kg} \mathrm{ha}^{-1}, 60 \mathrm{~kg} \mathrm{ha}^{-1}\right.$ e $\left.90 \mathrm{~kg} \mathrm{ha}^{-1}\right)$. As culturas antecessoras apresentaram efeitos na produtividade do feijoeiro, sendo o consórcio de milho e Urochloa, ambos inoculados, a melhor opção. A população inicial do feijoeiro não foi afetada pelas culturas antecessoras. A aplicação de nitrogênio em cobertura não interferiu na produtividade do feijoeiro, em cultivo irrigado de inverno, sob plantio direto.

PALAVRAS-CHAVE: Azospirillum brasilense; coberturas vegetais; nitrogênio mineral.

O uso da irrigação permitiu o surgimento de uma nova época para o cultivo do feijoeiro, que ficou conhecida como "feijão de inverno", com semeadura realizada de maio a julho (Nascimento et al. 2004). A semeadura, nesta época, permite aos produtores realizarem, em plantio direto, o cultivo sobre a palhada de culturas semeadas no verão. Dentre estas culturas, destaca-se o milho, como boa opção de cultura antecessora ao feijão.

1. Trabalho recebido em dez./2012 e aceito para publicação em ago./2013 (nº registro: PAT 21612).

2. Universidade Estadual Paulista (Unesp), Faculdade de Engenharia, Departamento de Fitotecnia, Tecnologia de Alimentos e Socioeconomia, Ilha Solteira, SP, Brasil.E-mails: michelletraete@hotmail.com,arf@agr.feis.unesp.br, ferreirajpferreira@gmail.com.

3. Universidade Estadual de Mato Grosso (Unemat), Departamento de Fitotecnia, Nova Xavantina, MT, Brasil.

E-mail: fhkaneko@hotmail.com. 
As plantas de cobertura, principalmente as gramíneas, integradas de forma planejada ao sistema de rotação de culturas, proporcionam alto potencial de produção de fitomassa de elevada relação $\mathrm{C} / \mathrm{N}$, garantindo a cobertura do solo por período mais longo (Borghi et al. 2008). No consórcio do milho com Urochloa, a forrageira pode ser utilizada para a formação de palhada no sistema plantio direto, durante o período que antecede o cultivo do feijão de inverno. Assim, o consórcio, manejado corretamente, proporciona aumento na quantidade de palha, visando à melhor cobertura do solo, para a realização da semeadura direta e, em alguns casos, aumento de produtividade na cultura sequente (Chioderoli et al. 2010). Ademais, no consórcio entre milho e forrageiras, a cultura subsequente pode ser favorecida pela ciclagem dos nutrientes acumulados na parte aérea da cultura intercalar (Batista et al. 2011).

O nitrogênio é um dos nutrientes mais absorvidos e importantes para o feijoeiro e, quando aplicado na dose recomendada, promove rápido crescimento das plantas, aumenta a folhagem e o teor de proteínas nas sementes e favorece micro-organismos do solo responsáveis pela decomposição de matéria orgânica, além de incrementar o teor de matéria seca, que é importante durante todo o ciclo, especialmente nas fases de floração e enchimento de grãos (Malavolta 1979).

De acordo com Fageria (1983), a capacidade de produção agrícola dos solos está diretamente relacionada com os seus teores de matéria orgânica e nitrogênio. Nos dias atuais, na maioria dos solos cultivados, é difícil manter um nível satisfatório destes dois componentes. Uma das técnicas capazes de possibilitar a economia de fertilizantes nitrogenados, pela fixação do nitrogênio, é a associação de gramíneas a bactérias diazotróficas do gênero Azospirillum. Deste modo, além de economia para os agricultores, o uso de inoculantes contendo Azospirillum brasilense, em gramíneas, contribui para o ambiente e poderá incrementar a qualidade química da palhada, além de fornecer nutrientes às culturas sucessoras (Hungria 2011).

Diante desses fatos, este trabalho objetivou avaliar a influência da cultura antecessora, constituída por milho e/ou Urochloa ruziziensis, associada à adubação nitrogenada em cobertura, sobre os componentes de produção e produtividade de grãos do feijoeiro, em cultivo de inverno (irrigado), sob sistema plantio direto.

\section{MATERIAL E MÉTODOS}

O experimento foi desenvolvido no ano agrícola 2011/2012, em área experimental da Faculdade de Engenharia da Universidade Estadual Paulista (Unesp), Campus de Ilha Solteira, SP (aproximadamente $20^{\circ} 22^{\prime} \mathrm{S}, 5^{\circ} 22^{\prime} \mathrm{W}$ e altitude de $335 \mathrm{~m}$ ). O solo predominante na área, conforme a nova denominação do Sistema Brasileiro de Classificação de Solos (Embrapa 2006), é o Latossolo Vermelho distrófico álico, de textura argilosa. As médias anuais de precipitação pluvial, temperatura e umidade relativa do ar são, respectivamente, $1.330 \mathrm{~mm}, 25^{\circ} \mathrm{C}$ e $66 \%$ (Centurion 1982).

Antes da instalação do experimento, foi coletada amostra composta de solo na área (vinte subamostras homogeneizadas e retiradas da camada 0,0-0,20 m), para análise química (Raij et al. 1996), cujos resultados foram: $\mathrm{P}$ (resina) $=12 \mathrm{mg} \mathrm{dm}^{-3}$; matéria orgânica $=15 \mathrm{~g} \mathrm{dm}^{-3} ; \mathrm{pH}\left(\mathrm{CaCl}_{2}\right)=5,1$; $\mathrm{K}=2,6 \mathrm{mmol}_{\mathrm{c}} \mathrm{dm}^{-3} ; \mathrm{Ca}=26 \mathrm{mmol}_{\mathrm{c}} \mathrm{dm}^{-3} ; \mathrm{Mg}=$ $13 \mathrm{mmol}_{\mathrm{c}} \mathrm{dm}^{-3} ; \mathrm{H}+\mathrm{Al}=16 \mathrm{mmol}_{\mathrm{c}} \mathrm{dm}^{-3} ; \mathrm{S}=11 \mathrm{mg} \mathrm{dm}^{-3}$.

$\mathrm{O}$ delineamento experimental utilizado foi o de blocos ao acaso, com quatro repetições, em esquema fatorial $8 \times 4$ (coberturas $\mathrm{x}$ doses de nitrogênio). Os tratamentos de cobertura estudados consistiram da combinação das culturas de cobertura, com ou sem a inoculação das sementes com A. Brasilense: 1) milho solteiro com sementes inoculadas; 2) milho solteiro sem sementes inoculadas; 3) U. ruziziensis solteira com sementes inoculadas; 4) U. ruziziensis solteira sem sementes inoculadas; 5) consórcio milho $\mathrm{x}$ U. ruziziensis com as sementes das duas espécies inoculadas; 6) consórcio milho x U. ruziziensis sem inoculação das sementes das duas espécies; 7) consórcio milho $\mathrm{x} U$. ruziziensis somente com sementes de milho inoculadas; 8) consórcio milho $\mathrm{x} U$. ruziziensis somente com sementes de $U$. ruziziensis inoculadas; e quatro doses de nitrogênio em cobertura no feijoeiro (0 kg ha-1, $30 \mathrm{~kg} \mathrm{ha}^{-1}, 60 \mathrm{~kg} \mathrm{ha}^{-1}$ e $\left.90 \mathrm{~kg} \mathrm{ha}^{-1}\right)$.

O milho, em cultivo solteiro, foi semeado com espaçamento de $0,90 \mathrm{~m}$ entre as linhas e 5,4 plantas por metro de sulco. Na mesma data, semeou-se Urochloa ruziziensis cv. Comum, em sistema solteiro, no espaçamento de $0,45 \mathrm{~m}$ entre as linhas e na quantidade de $20 \mathrm{~kg}$ de sementes por hectare. Já em consórcio com o milho, a Urochloa foi semeada em sulcos abertos nas entrelinhas, distanciadas $0,45 \mathrm{~m}$ das linhas de milho, utilizando-se $10 \mathrm{~kg}$ de sementes ha ${ }^{-1}$. 
A semeadura do milho foi realizada em 03/11/2011, utilizando-se o híbrido AG 8088 PRO. A adubação química básica, nos sulcos de semeadura (milho), constou de $300 \mathrm{~kg} \mathrm{ha}^{-1}$ da formulação 04-30-10. A inoculação das sementes de milho e braquiária ocorreu à sombra, com as estirpes $A b-V_{5}$ e $\mathrm{Ab}-\mathrm{V}_{6}$, utilizando-se $200 \mathrm{~g}$ de inoculante turfoso, com $2 \times 10^{8}$ células viáveis por grama do produto comercial, para cada $25 \mathrm{~kg}$ de sementes.

A adubação de cobertura foi efetuada na fase $\mathrm{V}_{5}$ do milho, em faixas ao lado das linhas de cultivo, utilizando-se $30 \mathrm{~kg} \mathrm{ha}^{-1}$ de $\mathrm{N}$, na forma de sulfato de amônio. Já a Urochloa não foi adubada. Após a colheita do milho, em 29/04/2012, foi realizada a dessecação da palhada com glyphosate ( $1.920 \mathrm{~g} \mathrm{ha}^{-1}$ de i.a.) e passagem do desintegrador mecânico.

O feijão foi semeado em 08/05/2012. Utilizou-se a cultivar Pérola (plantas de hábito de crescimento tipo III e grãos carioca), semeada mecanicamente, com o uso de semeadora-adubadora, para plantio direto. Utilizou-se espaçamento de $0,45 \mathrm{~m}$ nas entrelinhas e densidade de doze a treze sementes por metro, visando a garantir população de 220.000 plantas ha-1 $^{-}$.

$\mathrm{Na}$ semeadura, foram utilizados $250 \mathrm{~kg} \mathrm{ha}^{-1} \mathrm{da}$ fórmula 04-30-10 de NPK. A emergência das plântulas ocorreu uniformemente, para todos os tratamentos, aos cinco dias após a semeadura (13/05/2012). $\mathrm{O}$ fornecimento de água à cultura, nos períodos de estiagem, foi realizado por sistema de irrigação com pivô central, com lâmina de água de, aproximadamente, $13 \mathrm{~mm}$ e turno de rega de três dias.

As parcelas experimentais consistiram de sete linhas de 5,0 m de comprimento, tendo, como área útil, as cinco linhas centrais de cada parcela, desconsiderando-se 0,50 m nas extremidades de cada linha.

$A$ adubação nitrogenada em cobertura foi realizada no estádio $V_{4-4}$ do feijoeiro (quarta folha trifoliada), aproximadamente aos 25 dias após a emergência (DAE). O adubo foi distribuído manualmente, ao lado da linha da cultura, sobre a palhada, utilizando-se, como fonte, a ureia. Após a adubação, a área foi irrigada $(13 \mathrm{~mm})$, com o objetivo de incorporar o fertilizante ao solo.

O tratamento das sementes de feijão foi feito com o fungicida carbendazim + thiran $(45+105 \mathrm{~g}$ do i.a. $100 \mathrm{~kg}^{-1}$ de sementes), visando ao controle de doenças como a antracnose e podridão radicular. $\mathrm{O}$ controle de plantas daninhas, em pós-emergência, foi realizado com o herbicida fomesafen $\left(225 \mathrm{~g} \mathrm{ha}^{-1}\right.$ do i.a.), aos 17 DAE, juntamente com a aplicação da mistura deltametrina + triafós $\left(7,5+262 \mathrm{~g} \mathrm{ha}^{-1}\right.$ do i.a.) + mancozeb (1.500 g ha ${ }^{-1}$ do i.a.). Aos $32 \mathrm{DAE}$, aplicou-se, ainda, a mistura deltametrina + triafós $\left(7,5+262 \mathrm{~g} \mathrm{ha}^{-1}\right.$ do i.a. $)+$ carbendazim $\left(375 \mathrm{~g} \mathrm{ha}^{-1}\right.$ do i.a.) e, aos 46 e 64 DAE, novamente a mistura de deltametrina $\left(3,75 \mathrm{~g} \mathrm{ha}^{-1}\right.$ do i.a. $)+$ mancozeb (1.500 $\mathrm{g} \mathrm{ha}^{-1}$ do i.a.). A colheita foi realizada manualmente, aos 92 DAE (13/08/2012).

Avaliou-se, nas culturas antecessoras, a massa de matéria seca, determinada após a passagem de desintegrador mecânico, coletando-se os restos vegetais e utilizando-se quadrado de $0,50 \mathrm{~m}$ de lado e área de $0,25 \mathrm{~m}^{2}$, em dois pontos de cada parcela. O material foi levado para o laboratório, para secagem em estufa de ventilação forçada, à temperatura de $65^{\circ} \mathrm{C}$, até atingir massa em equilíbrio, e, então, procedeu-se à quantificação e extrapolação para $\mathrm{kg} \mathrm{ha}^{-1}$.

No feijoeiro, foram avaliadas as seguintes variáveis: População de plantas: aproximadamente aos 8 DAE e durante a colheita, contou-se o número de plantas em duas linhas de 4,0 m de comprimento de cada parcela e, em seguida, calculou-se a população inicial e a população final de plantas ha-1, Massa seca das plantas: por ocasião do florescimento pleno, coletaram-se oito plantas em linha da área útil e, em seguida, o material foi colocado em estufa de ventilação forçada, à temperatura média de $65^{\circ} \mathrm{C}$, até atingir massa em equilíbrio; Teor de nitrogênio nas folhas: foram utilizadas as folhas de quatro plantas coletadas em cada parcela, durante o período de florescimento pleno, e, após a secagem em estufa (circulação forçada de ar a $65^{\circ} \mathrm{C}$, até massa constante), as folhas foram moídas em moinho tipo Willey e, em seguida, foi realizada a digestão sulfúrica (Malavolta et al. 1997); Componentes de produção: na colheita, foram coletadas oito plantas na área útil de cada parcela, para determinação do número de vagens por planta, grãos por planta e grãos por vagem; Produtividade de grãos: arrancaram-se as plantas de duas linhas da área útil de cada parcela $(4,0 \mathrm{~m}$ de comprimento), as quais foram colocadas para secar a pleno sol, e, após a secagem, foram submetidas à trilha mecânica, os grãos pesados e os dados transformados em kg ha-1, corrigindo-se para 13\% (base úmida).

Os dados foram, inicialmente, submetidos à análise de variância e ao teste $\mathrm{F}$ (Snedecor). As médias das coberturas vegetais foram comparadas entre si pelo teste Tukey, a 5\%. Já o efeito das doses de nitrogênio foi analisado por regressão polinomial. Para estas análises, utilizou-se o software Sisvar (Ferreira 2007). 


\section{RESULTADOS E DISCUSSÃO}

O florescimento pleno do feijoeiro ocorreu aos 40 DAE e a cultura apresentou ciclo de 92 dias. As temperaturas mínimas, máximas e a precipitação total, durante a realização do experimento, encontram-se descritas na Figura 1. A precipitação pluvial foi de $102,3 \mathrm{~mm}$, durante os 92 dias, e complementada com irrigação $(300 \mathrm{~mm})$, a fim de atender às exigências de água do feijoeiro, ao longo do ciclo, situadas na faixa de 300-400 mm (Moreira et al. 2003).

Quanto à produção de matéria seca, observou-se que houve diferença significativa entre as culturas (milho x U. ruziziensis) solteiras, e as maiores quantidades de palha foram obtidas com U. ruziziensis, principalmente quando suas sementes foram inoculadas. Neste caso, foram produzidas mais de $11 \mathrm{t} \mathrm{ha}^{-1}$ de palhada e ambos os tratamentos diferiram, significativamente, daqueles com milho (Tabela 1).

Verificou-se que o milho solteiro inoculado produziu, em média, $25 \%$ a mais de cobertura vegetal do que o tratamento sem inoculação, sendo este o tratamento que produziu menor quantidade de cobertura vegetal (Tabela 1). Pode-se atribuir este resultado ao fato de que, apesar de a fixação biológica de nitrogênio por Azospirillum em gramíneas ser o principal objetivo de estudo, desde 1960, existem evidências de que parte da contribuição de bactérias deste gênero para as plantas deve-se à produção de fito-hormônios (Moreira et al. 2010). Desta forma, os estudos atuais destas bactérias diazotróficas são desenvolvidos com frequência, pois, além de incrementos de produtivi-

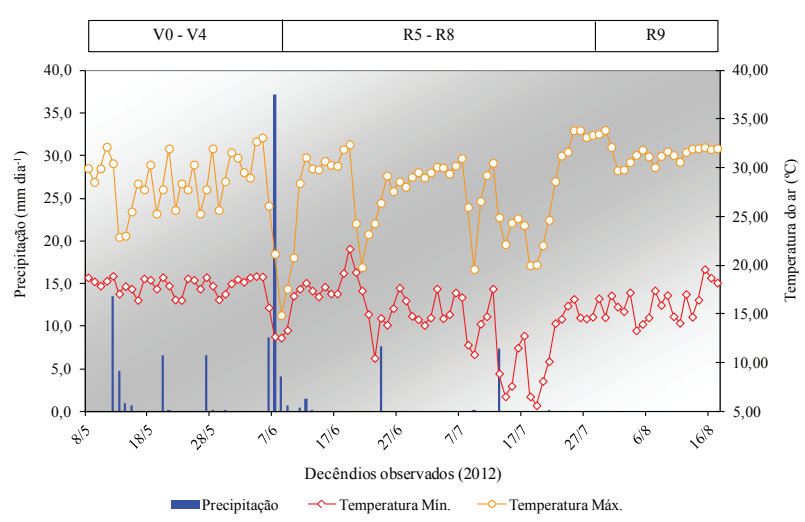

Figura 1. Precipitação pluvial $\left(\mathrm{mm} \mathrm{dia}^{-1}\right)$ e temperaturas máxima e mínima $\left({ }^{\circ} \mathrm{C}\right)$, obtidas na área experimental, de maio a agosto de 2012 (Selvíria, MS). V0-V4: fase vegetativa; R5-R8: fase reprodutiva - formação de estruturas vegetativas; R9: fase reprodutiva - maturação. dade, há evidências de sua contribuição no aumento do volume radicular e, consequentemente, exploração mais abrangente do substrato.

Hungria et al. (2010), avaliando a inoculação com estirpes selecionadas de $A$. brasilense e A. Lipoferum, na melhoria do rendimento de milho e trigo, comprovaram a absorção de macro e micronutrientes, pelas plantas inoculadas, além de aumento na eficiência do uso destes nutrientes. Quadros (2009), estudando a inoculação de Azospirillum spp. em milho, observou aumento no volume de raízes, nas cultivares avaliadas, bem como de matéria seca, na parte aérea das plantas, o que pareceu estar relacionado ao aumento das atividades de enzimas fotossintéticas. Outro trabalho que corrobora o aumento de matéria seca e o acúmulo de nutrientes em plantas assim inoculadas foi o desenvolvido por Reis Júnior et al. (2008).

Observou-se que as variáveis relacionadas à população de plantas (inicial e final) não apresentaram diferenças significativas para nenhum dos fatores estudados (Tabela 2). Assim, os valores apresentados não foram influenciados pelas coberturas vegetais e nem pelas doses de adubação nitrogenada aplicada em cobertura, e não houve interação entre elas. Isto mostra que a palhada não afetou a plantabilidade da máquina e a germinação das sementes.

Silveira et al. (2005) não observaram diferenças significativas, em relação ao estande final das plantas de feijão, ao compararem as coberturas vegetais constituídas pelos restos culturais de milho e U. brizantha, bem como do consórcio entre elas.

Tabela 1. Massa de matéria seca da palhada das diferentes coberturas, antes da semeadura do feijão (Selvíria, MS, safra 2011/2012).

\begin{tabular}{lc}
\hline \multicolumn{1}{c}{ Tratamento } & Cobertura vegetal \\
\cline { 2 - 2 } & $\mathrm{kg} \mathrm{ha}^{-1}$ \\
\hline Milho & $7.459 \mathrm{e}$ \\
Milho - inoculado (I) & $9.289 \mathrm{~cd}$ \\
Urochloa ruziziensis & $10.884 \mathrm{ab}$ \\
Urochloa ruziziensis inoculada (I) & $11.272 \mathrm{a}$ \\
Milho + Urochloa ruziziensis & $10.422 \mathrm{abc}$ \\
Milho (I) + Urochloa ruziziensis & $9.654 \mathrm{bcd}$ \\
Milho + Urochloa ruziziensis (I) & $9.140 \mathrm{~cd}$ \\
Milho (I) + Urochloa ruziziensis(I) & $8.691 \mathrm{de}$ \\
\hline F (Snedecor)/ Tratamentos & $16,63^{*}$ \\
\hline DMS & $1.448,10$ \\
\hline CV (\%) & 6,36 \\
\hline
\end{tabular}

${ }^{1}$ Médias seguidas de letras diferentes, na mesma coluna, diferem estatisticamente, pelo teste Tukey $(\mathrm{p}<0,05)$. 
Tabela 2. População inicial e final de plantas, massa seca de plantas e teor de nitrogênio foliar de feijoeiro (cv. Pérola), em função das coberturas vegetais e doses de nitrogênio aplicadas em cobertura, em cultivo de inverno, sob sistema plantio direto (Selvíria, MS, 2012).

\begin{tabular}{|c|c|c|c|c|c|}
\hline \multirow{2}{*}{ Tratamento } & & População inicial & População final & Massa seca & $\mathrm{N}$ foliar \\
\hline & & \multicolumn{2}{|c|}{ - plantas ha $^{-1}$} & g planta ${ }^{-1}$ & $\mathrm{~g} \mathrm{~kg}^{-1}$ \\
\hline \multicolumn{6}{|l|}{ Cobertura vegetal $(C)$} \\
\hline Milho & & 186.806 & 171.875 & 10,52 & 43,58 \\
\hline Milho inoculado (I) & & 199.306 & 182.292 & 11,80 & 44,89 \\
\hline Urochloa & & 188.194 & 176.042 & 11,60 & 43,58 \\
\hline Urochloa inoculada (I) & & 178.472 & 171.528 & 12,72 & 46,20 \\
\hline Milho + Urochloa & & 184.028 & 178.472 & 11,48 & 42,48 \\
\hline Milho (I) + Urochloa & & 185.764 & 173.958 & 12,07 & 45,78 \\
\hline Milho + Urochloa $(\mathrm{I})$ & & 198.264 & 181.944 & 11,10 & 44,16 \\
\hline Milho (I) + Urochloa (I) & & 188.889 & 180.556 & 12,29 & 45,72 \\
\hline \multicolumn{6}{|l|}{ Doses de $N\left(\mathrm{~kg} \mathrm{ha}^{-1}\right)(\mathrm{D})$} \\
\hline 0 & & 189.757 & 178.819 & $10,57^{(1)}$ & 45,17 \\
\hline 30 & & 189.930 & 176.910 & 11,46 & 44,86 \\
\hline 60 & & 187.674 & 176.215 & 12,03 & 43,91 \\
\hline 90 & & 187.500 & 176.389 & 12,75 & 44,24 \\
\hline \multirow{3}{*}{ Teste F } & $\mathrm{C}$ & $1,89^{\mathrm{ns}}$ & $0,55^{\mathrm{ns}}$ & $1,86^{\mathrm{ns}}$ & $1,87^{\mathrm{ns}}$ \\
\hline & $\mathrm{D}$ & $0,13^{\text {ns }}$ & $0,08^{\text {ns }}$ & $6,39 * *$ & $0,72^{\mathrm{ns}}$ \\
\hline & $\mathrm{C} \times \mathrm{D}$ & $1,91^{\mathrm{ns}}$ & $1,19^{\text {ns }}$ & $1,43^{\mathrm{ns}}$ & $1,64^{\mathrm{ns}}$ \\
\hline Média geral & & 188.715 & 177.083 & 11,69 & 44,57 \\
\hline $\mathrm{CV}(\%)$ & & 10,80 & 13,28 & 17,41 & 8,61 \\
\hline
\end{tabular}

Em relação à produção de matéria seca de plantas, as diferentes coberturas testadas não influenciaram, significativamente, nos resultados (Tabela 2). Porém, as doses aplicadas promoveram aumento linear de matéria seca $\left[\mathrm{y}=10,6420+0,0234 \mathrm{x}\left(\mathrm{r}^{2}=0,99\right)\right]$, até o fornecimento máximo de $\mathrm{N}\left(90 \mathrm{~kg} \mathrm{ha}^{-1}\right)$, que proporcionou acúmulo de $12,75 \mathrm{~g} \mathrm{planta}^{-1}$. Da mesma forma, Arf et al. (2008) e Kaneko et al. (2010), avaliando a adubação nitrogenada em cobertura, verificaram máximos incrementos na massa seca de plantas de feijoeiro cv. Pérola, nas doses de nitrogênio de

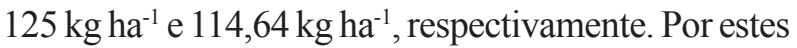
resultados, nota-se a importância do nitrogênio, o qual influencia na fotossíntese e promove o crescimento vegetativo do feijoeiro (Silveira \& Damasceno 1993).

Nos resultados para teor de $\mathrm{N}$ foliar, não houve diferenças significativas entre as coberturas vegetais e nem entre as doses de $\mathrm{N}$ aplicadas em cobertura (Tabela 2). Contudo, Soratto et al. (2008), estudando o manejo de $\mathrm{N}$ no feijoeiro cultivado em área onde, anteriormente, havia sido cultivado milho solteiro ou milho consorciado com U. brizantha, verificaram que a aplicação de $\mathrm{N}$ aumentou o teor deste elemento nas folhas do feijoeiro. Segundo os autores, isto pode estar relacionado com a maior ciclagem deste nutriente proporcionado pela forrageira. Mesmo nos tratamentos onde não foi realizada a adubação nitrogenada em cobertura, observou-se que os teores médios de nitrogênio foliar encontravam-se na faixa recomendada para a cultura, isto é, entre $30 \mathrm{~g} \mathrm{~kg}^{-1} \mathrm{e}$ $50 \mathrm{~g} \mathrm{~kg}^{-1}$ (Ambrosano et al. 1996).

Verificou-se que o número de vagens por planta não diferiu, significativamente, em relação às coberturas vegetais e nem entre as doses de nitrogênio em cobertura. Já para o número de grãos por planta, houve diferença significativa $(\mathrm{p}<0,05)$ entre as coberturas. O tratamento com Urochloa inoculada apresentou valor superior $(105,92)$ ao do tratamento com consórcio de milho + Urochloa, ambos sem inoculação $(79,38)$ (Tabela 3). Pôde-se verificar que este tratamento foi o que apresentou as menores quantidades de nitrogênio foliar (Tabela 2). Segundo Lopes et al. (2004), o nitrogênio é o nutriente que mais limita o desenvolvimento da planta, bem como a produtividade e a biomassa da maioria das culturas.

Para a quantidade de grãos por vagem, também não houve efeitos significativos $(p>0,05)$ de coberturas. Entretanto, as doses de nitrogênio aplicadas em cobertura tiveram efeito significativo $(p<0,05)$, com resposta quadrática sobre a variável dependente e 
Tabela 3. Quantidade de vagens por planta, grãos por planta e grãos por vagem, massa de cem grãos e produtividade de feijoeiro (cv. Pérola), em função das coberturas vegetais e doses de nitrogênio aplicadas em cobertura, em cultivo de inverno, sob plantio direto (Selvíria, MS, 2012).

\begin{tabular}{|c|c|c|c|c|c|c|}
\hline & \multirow{2}{*}{ Tratamento } & \multirow{2}{*}{$\begin{array}{l}\text { Vagens } \\
\text { planta }^{-1}\end{array}$} & \multirow{2}{*}{$\begin{array}{l}\text { Grãos } \\
\text { planta }^{-1}\end{array}$} & \multirow{2}{*}{$\begin{array}{c}\text { Grãos } \\
\text { vagem }^{-1}\end{array}$} & \multirow{2}{*}{$\frac{\text { Massa cem grãos }}{\mathrm{g}}$} & \multirow{2}{*}{$\frac{\text { Produtividade }}{\mathrm{kg} \mathrm{ha}^{-1}}$} \\
\hline & & & & & & \\
\hline \multicolumn{7}{|c|}{ Cobertura vegetal (C) } \\
\hline \multicolumn{2}{|c|}{ Milho } & 15,69 & $81,45 \mathrm{ab}$ & 5,21 & 26,83 & $3.371 \mathrm{bc}$ \\
\hline \multicolumn{2}{|c|}{ Milho inoculado (I) } & 16,39 & $89,30 \mathrm{ab}$ & 5,46 & 27,85 & $4.065 \mathrm{ab}$ \\
\hline \multicolumn{2}{|c|}{ Urochloa } & 16,81 & $91,03 \mathrm{ab}$ & 5,42 & 28,26 & $3.759 \mathrm{abc}$ \\
\hline \multicolumn{2}{|c|}{ Urochloa inoculada (I) } & 18,68 & $105,92 \mathrm{a}$ & 5,68 & 28,22 & $4.455 \mathrm{a}$ \\
\hline \multicolumn{2}{|c|}{ Milho + Urochloa } & 15,03 & $79,38 \mathrm{~b}$ & 5,27 & 25,69 & $3.596 \mathrm{bc}$ \\
\hline \multicolumn{2}{|c|}{ Milho (I) + Urochloa } & 16,59 & $89,81 \mathrm{ab}$ & 5,46 & 26,92 & $3.904 \mathrm{abc}$ \\
\hline \multicolumn{2}{|c|}{ Milho + Urochloa (I) } & 15,55 & $80,89 \mathrm{ab}$ & 5,18 & 27,70 & $3.224 \mathrm{c}$ \\
\hline \multicolumn{2}{|c|}{ Milho (I) + Urochloa (I) } & 14,81 & $82,8 \mathrm{ab}$ & 5,66 & 27,21 & $3.855 \mathrm{abc}$ \\
\hline \multicolumn{7}{|c|}{ Doses de N $\left(\mathrm{kg} \mathrm{ha}^{-1}\right)(D)$} \\
\hline \multicolumn{2}{|c|}{0} & 15,29 & 81,62 & $5,34^{(1)}$ & $26,01^{(2)}$ & 3.676 \\
\hline \multicolumn{2}{|c|}{30} & 16,37 & 91,25 & 5,61 & 27,14 & 3.782 \\
\hline \multicolumn{2}{|r|}{60} & 16,52 & 89,98 & 5,45 & 28,04 & 3.859 \\
\hline \multicolumn{2}{|r|}{90} & 16,58 & 87,46 & 5,26 & 28,16 & 3.799 \\
\hline \multirow{3}{*}{ Teste F } & $\mathrm{C}$ & $1,58^{\mathrm{ns}}$ & $2,41 *$ & $2,29^{\text {ns }}$ & $1,58^{\text {ns }}$ & $5,77 * *$ \\
\hline & $\mathrm{D}$ & $0,75^{\mathrm{ns}}$ & $1,17^{\mathrm{ns}}$ & $3,38^{*}$ & $4,22 * *$ & $0,44^{\mathrm{ns}}$ \\
\hline & C x D & $1,34^{\mathrm{ns}}$ & $1,24^{\mathrm{ns}}$ & $0,81^{\mathrm{ns}}$ & $0,91^{\mathrm{ns}}$ & $1,31^{\mathrm{ns}}$ \\
\hline \multicolumn{2}{|c|}{ Média geral } & 16,19 & 87,56 & 5,41 & 27,34 & 3.779 \\
\hline \multicolumn{2}{|c|}{ CV (\%) } & 24,29 & 25,58 & 8,70 & 10,01 & 17,22 \\
\hline
\end{tabular}

valor de máxima estimado em $50 \mathrm{~kg} \mathrm{ha}^{-1}$ de nitrogênio (5,85 grãos por vagem). Contrariamente, Silva (2002) e Soratto et al. (2004), em estudo semelhante, não observaram efeitos significativos de $\mathrm{N}$ em cobertura sobre o número de grãos por vagem. Apesar de esta variável ser considerada característica de alta herdabilidade genética, apresentando maiores diferenças entre cultivares do que dentro de cultivares, alguns resultados de pesquisas indicam que uma melhor nutrição em $\mathrm{N}$ pode aumentar o número de óvulos fertilizados por vagem, com os dados se ajustando a equações lineares crescentes (Santos et al. 2003, Arf et al. 2004, Soratto et al. 2006).

A massa de cem grãos não foi influenciada pelas coberturas vegetais avaliadas (Tabela 3). Já as doses de nitrogênio aplicadas em cobertura revelaram efeito linear crescente $[\mathrm{y}=26,2358+0,0245 \mathrm{x}$ $\left.\left(r^{2}=0,91\right)\right]$. Kaneko et al. (2010) também observaram aumento linear na massa de cem grãos, em um dos anos de condução de experimento semelhante. Já Arf et al. (2008), em estudo similar, citam que a massa de cem grãos está mais relacionada com as características genéticas da cultivar utilizada.

Quanto à produtividade de grãos, os tratamentos em que a cultura antecessora foi inoculada, tanto para o milho quanto para Urochloa, solteiros, apresentaram valores acima de $4.000 \mathrm{~kg} \mathrm{ha}^{-1}$ (Tabela 3 ). Contrariamente, Silveira et al. (2005), estudando a adubação nitrogenada em feijoeiro sob plantio direto, observaram menores produtividades do feijoeiro na sucessão à cultura do milho consorciado com Urochloa, em qualquer dose de nitrogênio.

$\mathrm{Na}$ presente pesquisa, mesmo não apresentando diferença significativa, a palhada de milho solteiro inoculado, quando comparada à de milho não inoculado, incrementou a produtividade do feijoeiro em, aproximadamente, $700 \mathrm{~kg} \mathrm{ha}^{-1}$. Todos os tratamentos apresentaram produtividades acima de $3.200 \mathrm{~kg} \mathrm{ha}^{-1}$, valores que corroboram os observados por Soratto et al. (2008). Estes autores, estudando o manejo do N, em feijoeiro cultivado em sucessão ao milho (solteiro ou consorciado com U. brizantha), obtiveram produtividades de grãos de, aproximadamente, $3.000 \mathrm{~kg} \mathrm{ha}^{-1}$, mesmo sem a utilização de adubação nitrogenada.

Na presente pesquisa, não houve efeito $(p>0,05)$ das doses de adubação nitrogenada sobre a produtividade de grãos (Tabela 3). Da mesma forma, Gomes Júnior (2006) não verificou efeito dos níveis de $\mathrm{N}$ em cobertura sobre a produtividade do feijoeiro em 
plantio direto sobre palhada de milheto e Urochloa. Este mesmo autor citou que o feijoeiro, em plantio direto, responde muito pouco a altas doses de $\mathrm{N}$ em cobertura, quando há grande aporte de fitomassa sobre a superfície do solo.

Contudo, Soratto et al. $(2005,2006)$ e Crusciol et al. (2007) notaram aumento na produtividade do feijoeiro em plantio direto, com a aplicação de N em cobertura. Segundo Pelegrin et al. (2009), a variabilidade nas respostas do feijoeiro às doses de $\mathrm{N}$, em diferentes experimentos, tem sido observada especialmente em razão dos níveis de fertilidade do solo e das técnicas empregadas nos sistemas produtivos, dentre as quais destaca-se o uso de sistemas de irrigação.

Desse modo, a ausência de respostas à adubação nitrogenada aqui observada pode estar relacionada ao cultivo contínuo. De acordo com Kluthcouski et al. (2005), principalmente em plantio direto, há tendência de se acumular nutrientes no perfil explorado pelas raízes, tornando menos frequente a resposta à adubação com macro e micronutrientes.

\section{CONCLUSÕES}

1. A produtividade do feijoeiro apresentou bom resultado, em sucessão ao milho inoculado + U. ruziziensis inoculada, considerando-se a produtividade do feijoeiro e a possibilidade de produzir grãos de milho, e, ao mesmo tempo, aumentar a produção de palha.

2. A aplicação de nitrogênio em cobertura não interferiu na produtividade do feijoeiro, em cultivo irrigado de inverno, sob plantio direto.

\section{REFERÊNCIAS}

AMBROSANO, J. E. et al. Feijão. In: RAIJ, B. V. et al. (Eds.). Recomendações de adubação e calagem para o Estado de São Paulo. 2. ed. Campinas: Instituto Agronômico, 1996. p. 194-195.

ARF, O. et al. Manejo do solo, água e nitrogênio no cultivo de feijão. Pesquisa Agropecuária Brasileira, Brasília, DF, v. 39, n. 2, p. 131-138, 2004.

ARF, O. et al. Mecanismos de abertura do sulco e adubação nitrogenada no cultivo do feijoeiro em sistema plantio direto. Bragantia, Campinas, v. 69, n. 1, p. 499-506, 2008.

BATISTA, K. et al. Acúmulo de matéria seca e de nutrientes em forrageiras consorciadas com milho safrinha em função da adubação nitrogenada. Pesquisa Agropecuária Brasileira, Brasília, DF, v. 46, n. 10, p. 1154-1160, 2011.

BORGHI, E. et al. Influência da distribuição espacial do milho e da Brachiaria brizantha consorciados sobre a população de plantas daninhas em sistema plantio direto na palha. Planta Daninha, Viçosa, v. 26, n. 3, p. 559-568, 2008.

CENTURION, J. F. Balanço hídrico da região de Ilha Solteira. Cientifica, Jaboticabal, v. 10, n. 1, p. 57-61, 1982.

CHIODEROLI, C. A. et al. Consorciação de braquiárias com milho outonal em plantio direto sob pivô central. Engenharia Agrícola, Jaboticabal, v. 30, n. 6, p. 11011109, 2010.

CRUSCIOL, C. A. C. et al. Fontes e doses de nitrogênio para o feijoeiro em sucessão a gramíneas no sistema plantio direto. Revista Brasileira de Ciência do Solo, Viçosa, v. 31, n. 6, p. 1545-1552, 2007.

EMPRESA BRASILEIRA DE PESQUISA AGROPECUÁRIA (Embrapa). Sistema brasileiro de classificação de solos. 2. ed. Rio de Janeiro: EmbrapaCNPS, 2006.

FAGERIA, N. K. Manejo químico do solo. In: FAGERIA, N. K. Cultura do arroz de sequeiro: fatores afetando a produtividade. Piracicaba: Instituto da Potassa e do Fosfato, 1983. p. 239-260.

FERREIRA, D. F. Sistema de análises de variância para dados balanceados. Lavras: UFLa, 2007.

GOMES JÚNIOR, F. G. Nitrogênio no feijoeiro em sistema de plantio direto sobre diferentes palhadas: produtividade, composição química e qualidade fisiológica de sementes. 2006. 106 f. Dissertação (Mestrado em Agronomia) Faculdade de Engenharia, Universidade Estadual Paulista, Ilha Solteira, 2006.

HUNGRIA, M. et al. Inoculation with selected strains of Azospirillum brasilense and A. lipoferum improves yields of maize and wheat in Brazil. Plant and Soil, Amsterdam, v. 331, n. 1/2, p. 413-425, 2010.

HUNGRIA, M. Inoculação com Azospirillum brasilense: inovação em rendimento a baixo custo. Londrina: Embrapa Soja, 2011. (Documentos, 395).

KANEKO, F. H. et al. Mecanismos de abertura de sulcos, inoculação e adubação nitrogenada em feijoeiro em sistema plantio direto. Bragantia, Campinas, v. 69, n. 1, p. 125-133, 2010.

KLUTHCOUSKI, J. et al. Manejo antecipado do nitrogênio nas principais culturas anuais. Santo Antônio de Goiás: Embrapa Arroz e Feijão, 2005. (Documentos, 188). 
LOPES, A. S. et al. Sistema plantio direto: bases para o manejo da fertilidade do solo. São Paulo: Associação Nacional para Difusão de Adubos, 2004.

MALAVOLTA, E. Adubos nitrogenados. In: MALAVOLTA, E. Abc da adubação. 4. ed. São Paulo: Agronômica Ceres, 1979. p. 25-39.

MALAVOLTA, E.; VITTI, G. C.; OLIVEIRA, S. A. Avaliação do estado nutricional das plantas: princípios e aplicações. Piracicaba: Potafos, 1997.

MOREIRA, F. M. et al. Bactérias diazotróficas associativas: diversidade, ecologia e potencial de aplicações. Comunicata Scientiae, Bom Jesus, v. 1, n. 2, p. 74-99, 2010.

MOREIRA, J. A. A. et al. (Eds.). Feijão: o produtor pergunta, a Embrapa responde. Brasília, DF: Embrapa Informação Tecnológica, 2003.

NASCIMENTO, M. S.; ARF, O.; SILVA, M. G. Resposta do feijoeiro à adubação de nitrogênio em cobertura e molibdênio via foliar. Acta Scientiarum Agronomy, Maringá, v. 26, n. 2, p. 153-159, 2004.

PELEGRIN, R. et al. Resposta da cultura do feijoeiro à adubação nitrogenada e à inoculação com rizóbio. Revista Brasileira de Ciência do solo, Viçosa, v. 33, n. 1, p. 219226, 2009.

QUADROS, P. D. de. Inoculação de Azospirillum spp. em sementes de genótipos de milho cultivados no Rio Grande do Sul. 2009. 62 f. Dissertação (Mestrado em Ciência do Solo) - Universidade Federal do Rio Grande do Sul, Porto Alegre, 2009.

RAIJ, B. V. et al. Recomendações de adubação e calagem para o Estado de São Paulo. 2. ed. Campinas: Instituto Agronômico, 1996. (Boletim técnico, 100).

REIS JÚNIOR, F. B. et al. Inoculação de Azospirillum amazonense em dois genótipos de milho sob diferentes regimes de nitrogênio. Revista Brasileira de Ciência do solo, Brasília, DF, v. 32, n. 3, p. 1139-1146, 2008.
SANTOS, A. B. dos et al. Resposta do feijoeiro ao manejo de nitrogênio em várzeas tropicais. Pesquisa Agropecuária Brasileira, Brasília, DF, v. 38, n. 11, p. 1265-1271, 2003.

SILVA, T. R. B. Adubação nitrogenada e resíduos vegetais no desenvolvimento do feijoeiro (Phaseolus vulgaris $L$.) em sistema de plantio direto. 2002. 56 f. Dissertação (Mestrado em Agronomia) - Faculdade de Engenharia, Universidade Estadual Paulista, Ilha Solteira, 2002.

SILVEIRA, P. M. da; DAMASCENO, M. A. Doses e parcelamento de $\mathrm{K}$ e de $\mathrm{N}$ na cultura do feijoeiro irrigado. Pesquisa Agropecuária Brasileira, Brasília, DF, v. 28, n. 11, p. 1269-1276, 1993.

SILVEIRA, P. M. et. al. Adubação nitrogenada no feijoeiro cultivado sob plantio direto em sucessão de culturas. Pesquisa Agropecuária Brasileira, Brasília, DF, v. 40, n. 4, p. 377-381, 2005.

SORATTO, R. P.; CARVALHO, M. A. C.; ARF, O. Nitrogênio em cobertura no feijoeiro cultivado em plantio direto. Revista Brasileira de Ciência do Solo, Viçosa, v. 30, n. 2, p. 259-265, 2006.

SORATTO, R. P.; CARVALHO, M. A. C.; ARF, O. Teor de clorofila e produtividade do feijoeiro em razão da adubação nitrogenada. Pesquisa Agropecuária Brasileira, Brasília, DF, v. 39, n. 9, p. 895-901, 2004.

SORATTO, R. P. et al. Aplicação tardia de nitrogênio no feijoeiro em plantio direto. Bragantia, Campinas, v. 64, n. 2, p. 211-218, 2005.

SORATTO, R. P. et al. Épocas de antecipação do nitrogênio para feijoeiro no sistema plantio direto após milho solteiro ou consorciado com Brachiaria brizantha. In: FERTBIO 2008, Londrina. Resumos... Londrina: Sociedade Brasileira de Ciência do Solo, 2008. 1 CD-ROM.

TSUMANUMA, G. M. Desempenho do milho consorciado com diferentes espécies de brachiarias, em Piracicaba, SP. 2004. 100 f. Dissertação (Mestrado em Fitotecnia) - Escola Superior de Agricultura "Luiz de Queiroz", Universidade de São Paulo, Piracicaba, 2004. 